\title{
Characterizations of Bacterial Vaginosis among HIV-positive and HIV-negative Pregnant Women
}

\author{
Samuel M. Adelaiye*, MB.BS, PGDCS, FWACS; S. O. Shittu, FWACS,DRH.FICS; \\ A.T. Olayinka, MB.BS, FMCPath, MPH \\ Federal Medical Centre, Azare, Bauchi State, Nigeria \\ Ahmadu Bello University Teaching Hospital, Zaria, Nigeria
}

\begin{abstract}
Objective: The aim of this study was to find the characteristics of bacterial vaginosis (BV) among HIV-infected and HIVnegative pregnant women at ABUTH, Zaria.

Study design: Case control and laboratory-based design, conducted from August 2, 2011, to December 30, 2011. BV was defined using Amsel's criteria, which uses 3 out of 4 diagnostic criteria to diagnose BV.

Results: Two hundred HIV-positive and 200-HIV negative women were included in the study. The mean age was 26.3 years with a range from 17 to 41 years. The prevalence rate of BV irrespective of HIV status was $33.2 \%$. In HIV-positive pregnant women, the prevalence was $46.0 \%$; in HIV-negative pregnant women, the prevalence was $20.5 \%$ (OR=3.30; $95 \%$ CI: 2.1-5.1, $P<0.05$ ). Hence, HIV-positive pregnant women were significantly more likely to have BV. BV was most prevalent in the age group of 30 to 34 years, with $49 \%$ positive, and in those with parity between 1 and 4 , with a prevalence of $41.5 \%$. It is least common in primigravidae with $19 \%$. Prevalence among HIV-positive pregnant women whose CD4 $>350 \mathrm{cell} / \mathrm{s} / \mathrm{mm}^{3}$ was $22 \%$, and for those whose CD4 was $<350$ cells $/ \mathrm{mm}^{3}$ prevalence was $67 \%$ (OR=7.05; 95\% CI: $\left.3.7-13.3, P<0.05\right)$.

Conclusion: BV is more prevalent among HIV-positive pregnant women than their HIV-negative counterparts, and its occurrence is higher among those with the lower CD4 count; therefore, reducing the prevalence of HIV among pregnant women and improving the CD4 count among HIV-positive pregnant women would reduce the prevalence of BV and its consequences.

(Int J Biomed. 2015;5(3):141-146.)
\end{abstract}

Keywords: Bacterial Vaginosis; HIV transmission; Amsel's criteria.

\section{Introduction}

$\mathrm{BV}$ is a common vaginal infection that involves the disruption of the balance of bacterial flora in the vagina with the overgrowth of specific bacteria. Normally, bacteria belonging to the Lactobacillus type live in the vagina as commensals. In BV, however, increased numbers of bacteria, such as Gardnerella vaginalis, Bacteroides spp, Mobiluncus spp, Prevotella spp and Mycoplasma hominis, replace them [1]. The reported prevalence of $\mathrm{BV}$ in pregnant women ranges from $14 \%$ to $21 \%$ in Western countries [2-4], and a prevalence rate of $40.8 \%$ was reported in a non-pregnant population in southern Nigeria [5]. A case study done in Ghana showed a

*Corresponding author: Adelaiye, Samuel Makanju (MB. BS, PGDCS, FWACS). Federal Medical Centre, Azare, Bauchi State, Nigeria. Email: samueladelaiye@yahoo.com low prevalence of $1.4 \%$ among antenatal women [4]. An estimated $25 \%$ to $30 \%$ of women have BV at any time, mostly without signs such as fishy odor or discharge [1,4], and this rises to $85 \%$ in prostitute populations [2,3].

A study of pregnant women demonstrated that women who had BV on screening were 5 times more likely to have preterm labor or late miscarriage than those without the condition [5]. In women delivered by Caesarean section, those with BV were nearly 6 times more likely to develop postpartum endometritis than those without BV despite antibiotic prophylaxis, and $\mathrm{BV}$ was the strongest predictor of postpartum endometritis irrespective of mode of delivery [6]. Of greater clinical importance is the link between BV and HIV infection. Apart from its association with adverse pregnancy outcomes, BV is associated with increased risk of sexual acquisition of HIV $[1,3,8]$. There is evidence to support several mechanisms through which BV and other reproductive tract infections facilitate HIV transmission [7]. Genital tract 
infection with $G$. vaginalis, which is commonly isolated in $\mathrm{BV}$, has been shown to be able to stimulate HIV-1 reproduction and hence increase the likelihood of sexual transmission [8]. Measurement of HIV in genital secretions indicates that HIV infectiousness and susceptibility may be greater in the presence of concurrent reproductive tract infections $[8,9]$. Also significant is the sharp decline in the concentration of HIV in genital secretions when the infection is treated $[1,2,8]$.

Several cross-sectional studies performed in Thailand, Uganda, and Malawi, showed that BV women had an increased incidence of HIV infection. A prospective study in Kenya also showed that the presence of BV and the absence of lactobacilli or absence of hydrogen peroxide-producing lactobacilli upon examination, were all significantly associated with acquisition of HIV infection at follow-up [1,2]. Studies of the impact of $\mathrm{BV}$ on HIV infections showed varying degrees of increased risk of infection [2]. Some investigators calculate that in a population where the baseline risk of seroconversion is $2 \%$, one additional case of HIV infection would occur for every 80 to 90 cases of vaginosis. "These data suggest that greater attention needs to be given to bacterial vaginosis in the global fight against HIV infection" [1].

In view of the relationship between $\mathrm{BV}$ and HIV infection and also the associated risk of adverse obstetric sequelae, including increased vertical transmission of HIV during pregnancy, screening women for $\mathrm{BV}$ and treating those infected is a major strategy in the primary and secondary prevention of HIV as well as reducing risk of mother-to-child transmission of HIV, particularly in settings of high HIV seroprevalence.

\section{The aim and objectives}

The aim of this study was to find the characteristics of $\mathrm{BV}$ among HIV-infected and HIV-negative pregnant women at ABUTH, Zaria

The specific objectives are to:

- Determine the prevalence of BV among HIV-infected pregnant women

- Determine the prevalence of BV among HIV-negative pregnant women

- Compare the prevalence of BV in the two groups

- Ascertain any relationship between the presence of $\mathrm{BV}$ and the immunological status of HIV-infected pregnant women

- Derive recommendations relevant to BV that will benefit the study population, and could be scaled up

Null Hypothesis: There is no statistically significant difference in the prevalence of BV between pregnant women who are HIV-positive and those who are HIV-negative in the same clinical setting.

\section{Materials and Methods}

\section{Studv area and design}

The study was case controlled in design and involved both clinical and laboratory- based components. The clinical segment of the study was carried out simultaneously at the
PMTCT and antenatal clinics of ABUTH, while the laboratory analyses were made at the AIDS Prevention Initiative in Nigeria (APIN)/Harvard/PEPFAR supported laboratory of ABUTH, Zaria.

The study participants were selected from the antenatal clinic after obtaining informed written consent for participation in the study.

The sample size for the study was determined using the formula below, and BV prevalence among HIV-negative pregnant women of $14 \%$ [1-4].

$$
\mathrm{N}=\frac{Z^{2} \mathrm{pq}}{D 2} \text {, where }
$$

$\mathrm{N}$ - Minimum sample size

Z- 1.96 at $95 \%$ confidence level

$\mathrm{P}$ - Prevalence of the condition

D- Level of significance, 0.05 at $95 \%$ confidence level

This gave a minimum sample size of 185 for each group. A $10 \%$ attrition rate was 18.5 ; this was approximated to 15 , giving a total of 200 for HIV-positive pregnant women and 200 for HIV-negative pregnant women as controls for the study.

For every HIV-infected patient recruited at the PMTCT clinic, an HIV-uninfected patient of similar age, parity, and socioeconomic status was recruited as control from the ANC until the total number of 200 was obtained in both groups (Table 1 and 2). Using convenience sampling technique, we selected consecutive pregnant women who consented and met the inclusion criteria.

Table 1.

Age and parity of both groups'patients

\begin{tabular}{|l|c|c|r|r|r|r|r|}
\hline & \multicolumn{3}{|c|}{$\begin{array}{c}\text { Parity of HIV- } \\
\text { positive pregnant } \\
\text { women }\end{array}$} & \multicolumn{3}{c|}{$\begin{array}{c}\text { Parity of HIV- } \\
\text { negative pregnant } \\
\text { women }\end{array}$} & \\
\hline Age group & 0 & $1-4$ & $\geq 5$ & 0 & $1-4$ & $\geq 5$ & Total \\
\hline $15-19$ & 3 & 4 & - & 3 & 4 & - & 14 \\
\hline $20-24$ & 14 & 30 & - & 14 & 30 & - & 88 \\
\hline $25-29$ & 12 & 44 & 2 & 12 & 44 & 2 & 116 \\
\hline $30-34$ & 8 & 31 & 10 & 8 & 31 & 10 & 98 \\
\hline $35-39$ & 4 & 14 & 15 & 4 & 14 & 15 & 66 \\
\hline$\geq 40$ & - & 6 & 3 & - & 6 & 3 & 18 \\
\hline Total & 41 & 129 & 30 & 41 & 129 & 30 & 400 \\
\hline
\end{tabular}

Those diagnosed with BV were treated free-of-charge using tabs Metronidazole $400 \mathrm{mg}, 8$ hourly, for 7 days.

The following criteria were used to select the participants for the study:

- Informed consent to participate in the study

- Those women who had gone through HIV pre-test counseling and testing (HCT) by ABUTH PMTCT 
nurse counselors

- Those who were reported as HIV-positive after undergoing the double rapid serial testing according to the National HIV Testing Algorithm and received post-test counseling

- Pregnant women who were reported as HIV-negative by double rapid serial testing and received post-test counseling were recruited as controls (matched for age and parity).

- The diagnosis of BV was based on the Amsel diagnostic criteria (Table 3) [9].

Table 2.

Socio-demographic data of patients

\begin{tabular}{|c|c|c|c|c|c|}
\hline \multirow{2}{*}{ Variable } & \multicolumn{2}{|c|}{ HIV-positive } & \multicolumn{2}{|c|}{ HIV-negative } & \multirow{2}{*}{ Total } \\
\hline & $\mathrm{n}$ & $\%$ & $\mathrm{n}$ & $\%$ & \\
\hline $\begin{array}{l}\text { Marital Status } \\
\text { Married } \\
\text { Single } \\
\text { Divorced } \\
\text { Widowed }\end{array}$ & $\begin{array}{c}198 \\
- \\
- \\
2\end{array}$ & $\begin{array}{c}49.7 \\
- \\
- \\
100\end{array}$ & $\begin{array}{c}200 \\
- \\
- \\
0\end{array}$ & $\begin{array}{c}50.3 \\
- \\
- \\
0\end{array}$ & 398 \\
\hline $\begin{array}{l}\text { Highest Educatio } \\
\text { Primary } \\
\text { Secondary } \\
\text { Tertiary } \\
\text { Quranic } \\
\text { None }\end{array}$ & $\begin{array}{c}\text { al Atta } \\
22 \\
70 \\
74 \\
28 \\
6\end{array}$ & $\begin{array}{l}\operatorname{ment} \\
68.8 \\
53.0 \\
40.0 \\
62.2\end{array}$ & $\begin{array}{r}10 \\
62 \\
111 \\
17 \\
4\end{array}$ & $\begin{array}{l}31.2 \\
47.0 \\
60.0 \\
37.8\end{array}$ & $\begin{array}{r}32 \\
132 \\
181 \\
45 \\
10\end{array}$ \\
\hline $\begin{array}{l}\text { Marriage Order } \\
\text { First } \\
\text { Second } \\
\text { Third }\end{array}$ & $\begin{array}{r}122 \\
74 \\
4\end{array}$ & $\begin{array}{l}39.1 \\
91.3 \\
57.1\end{array}$ & $\begin{array}{c}190 \\
7 \\
3\end{array}$ & $\begin{array}{r}60.9 \\
8.4 \\
42.8\end{array}$ & $\begin{array}{r}312 \\
81 \\
7\end{array}$ \\
\hline $\begin{array}{l}\text { Marriage Type } \\
\text { Monogamy } \\
\text { Polygamy }\end{array}$ & $\begin{array}{r}140 \\
60\end{array}$ & $\begin{array}{l}47 \\
58.8\end{array}$ & $\begin{array}{r}158 \\
42\end{array}$ & $\begin{array}{l}53.0 \\
41.2\end{array}$ & $\begin{array}{l}298 \\
102\end{array}$ \\
\hline $\begin{array}{l}\text { Total Number of } \\
1-2 \\
3 \text { or more } \\
\text { Missing:54(13.5\% }\end{array}$ & $\begin{array}{c}\text { artner } \\
100 \\
76\end{array}$ & $\begin{array}{c}\text { er time } \\
50.2 \\
51.7\end{array}$ & $\begin{array}{l}99 \\
71\end{array}$ & $\begin{array}{l}49.8 \\
48.3\end{array}$ & $\begin{array}{l}199 \\
147\end{array}$ \\
\hline
\end{tabular}

Table 3.

The Diagnosis of $B V$ based on the Amsel diagnostic criteria

\begin{tabular}{|l|c|c|c|c|}
\hline \multirow{2}{*}{$\begin{array}{c}\text { Laboratory } \\
\text { findings }\end{array}$} & \multicolumn{2}{|c|}{ HIV-positive } & \multicolumn{2}{c|}{ HIV-negative } \\
\cline { 2 - 5 } & $\begin{array}{c}\text { positive } \\
\mathrm{n}(\%)\end{array}$ & $\begin{array}{c}\text { negative } \\
\mathrm{n}(\%)\end{array}$ & $\begin{array}{c}\text { positive } \\
\mathrm{n}(\%)\end{array}$ & $\begin{array}{c}\text { negative } \\
\mathrm{n}(\%)\end{array}$ \\
\hline Whiff test & $108(27 \%)$ & $88(22 \%)$ & $102(25 . \%)$ & $80(20 \%)$ \\
$\mathrm{PH}(>4.5)$ & $102(26 \%)$ & $100(25 \%)$ & $132(33 \%)$ & $76(19 \%)$ \\
Clue cells & $125(31.2 \%)$ & $92(23 \%)$ & $58(14.5 \%)$ & $73(18.2 \%)$ \\
V. discharge & $106(26.5 \%)$ & $142(35.5 \%)$ & $56(14 \%)$ & $137(34.2 \%)$ \\
\hline
\end{tabular}

Approval for the study was obtained from the ABUTH Ethical Review Committee. Doctor and nurse interviewers who were specifically trained for the study screened each woman for eligibility, explained the purpose and practice of the study and obtained informed written consent, which was written in English and translated for those who could not read English.

The instrument used was a pre-tested, semi-structured proforma. It was used to collect socio-demographic information, medical history, HIV infection characteristics, clinical "bedside" test results, and BV laboratory findings. Trained nurses and the author administered the questionnaire. The clinical "bedside" test was done by the author, and other information, such as CD4 count, was obtained from the patients' records. The laboratory scientist filled in the laboratory (clue cells) findings

The data assembled on the questionnaires were cleaned. A database was developed using SPSS 16.0 version for Windows and data entry was made into it. Further data cleaning was done before analysis was commenced, and relevant tables and graphs were generated where appropriate. The chi-square test was used to determine the strength of association between exposure and outcome variables in the experimental and controlled groups. A probability value of $P<0.05$ was considered statistically significant.

Specimen materials for making laboratory diagnosis were collected during a comprehensive pelvic examination. Following adequate counselling, each subject was placed in the dorsal position on an examination couch in the clinic. Using a sterile disposable Cusco speculum to expose the cervix and posterior fornix, the clinician evaluated the nature of the discharge, and a specimen from the posterior fornix was taken with a sterile swab stick. The classical BV discharge is characterized by a thin, homogeneous discharge, grey/ yellow in colour. However, absence of the classical discharge did not rule out disturbed vaginal flora. Two basic methods of diagnostic testing were used: laboratory-based and clinical 'bedside' testing. For the purposes of laboratory-based testing, the swab was taken from the posterior vaginal fornix, diluted with normal saline and allowed to air dry, then kept in a slide rack which was used to transport the slides to the laboratory where they were gram stained and examined under the microscope (X400).

\section{Diagnosis of BV by Amsel Criteria (Amsel et a.l, 1983)}

The $\mathrm{pH}$ of the vagina was determined directly with the use of Combi $9 \mathrm{pH}$ sticks placed on the posterior-vaginal fornix, after exposing the cervix with a sterile Cusco speculum that was inserted into the subject placed in the dorsal position. A swab stick was used to obtain a specimen which was then extracted into $0.2 \mathrm{~mL}$ of physiological saline on a glass slide. A drop of $10 \%$ potassium hydroxide was placed on another glass slide. The swab was then stirred in the $10 \%$ potassium hydroxide and immediately evaluated for the presence of a fishy odor. The extracted drop was placed in a slide rack and allowed to air dry. The slides were transported to the laboratory for examination, for detection of clue cells by Gram stain microscopy, which was examined under X100 objective for clue cells, at ART laboratory of the Ahmadu Bello University Teaching Hospital, Zaria.

Limitation of the study: a) The fact that Amsel's criteria used 3 of 4 diagnostic criteria made diagnosis very cumbersomeb) The unavailability of a single diagnostic test made the study unduly expensive; c) Matching of the patient for age parity was difficult; We had to obtain the sample on different days. 


\section{Results}

1. The 200 HIV-negative pregnant women that were ultimately recruited as controls in this study were secured from 239 eligible women: 15 were dropped during the process of matching for age and parity of the study group; 15 failed to return/complete the consent forms, and another 9 were replaced after their specimens encountered a number of mix-ups in the laboratory. To secure the 200 sample size of HIV-positive pregnant women, a total of 209 eligible women were recruited, with the following attrition: 3 women failed to return/complete the consent forms, 4 had wrong numbering of specimens in the laboratory, and 2 incurred broken slides, also in the laboratory.

This study was conducted between August 2 and December 30, 2011, during which period a total of 757 new antenatal attendees were seen in the facility where the study was carried out. Out of these 98 were HIV-positive, 7 of whom were newly diagnosed with HIV. This gave a clinical HIV prevalence of $12.9 \%$ during the study period. The overall prevalence rate of BV in this study irrespective of HIV status was $33.2 \%$.

2. Prevalence of BV among HIV-positive pregnant women was $46.0 \%$ (Table 4 ).

Table 4.

Prevalence of $B V$ and $H I V$ status of pregnant women at ABUTH Zaria

\begin{tabular}{|l|c|c|c|c|c|}
\hline \multirow{3}{*}{ HIV status } & \multicolumn{5}{|c|}{$\mathrm{BV}$} \\
\cline { 2 - 6 } & $\begin{array}{c}\text { positive } \\
\mathrm{n}(\%)\end{array}$ & $\begin{array}{c}\text { negative } \\
\mathrm{n}(\%)\end{array}$ & $P$ & OR & $95 \% \mathrm{CI}$ \\
\hline HIV-negative & $\begin{array}{c}41(20.5 \%) \\
\text { HIV-positive }\end{array}$ & $\begin{array}{c}159(79.5 \%) \\
108(54.0 \%)\end{array}$ & 0.000 & 3.30 & $2.1-5.1$ \\
\hline Total & $133(33.2 \%)$ & $267(66.8 \%)$ & & & \\
\hline
\end{tabular}

In this HIV group, BV was more commonly associated with tribe, religion, and parity, with $P$-values of $0.001,0.03$ and 0.04 , respectively, which were all statistically significant. Other factors that did not show any statistical significance were level of educational attainment, order of marriage, type of marriage, number of partners over time, age of the subject, occupation, and gestational age, with $P$-values of $0.07,0.62,0.36,0.22,0.06,0.28$ and 0.055 , respectively, as their $P$-values were $>0.05$.

3. BV prevalence among pregnant women who were HIV-negative was $20.5 \%$

In those who were HIV-negative, BV appeared to be more commonly associated with level of educational attainment and the age of the subject, with $P$-values of 0.024 and 0.025 , respectively, which were both statistically significant. Other factors that did not show any statistical significance were order of marriage, type of marriage, number of partners over time, tribe, religion occupation, gestational age, and parity, with $P$-values of $0.25,0.28,0.31,0.29,0.40,0.34,0.49$ and 0.29 , respectively, as their $P$-values were $>0.05$.

4. The odds of occurrence of BV in HIV-infected women was 3 times higher than among HIV-uninfected women $(\mathrm{OR}=3.30$; 95\% CI: 2.1-5.1, $P<0.05)$.

5 . The pattern of BV prevalence among those who were HIV-positive at various levels of CD4 count were as follows: For those with CD4 $>350$ cells $/ \mathrm{mm}^{3}$ the prevalence rate was $22 \%$, and for those with CD4 $<350$ cells $/ \mathrm{mm}^{3}$ the rate was $67 \%$. The odds of BV occurrence in HIV-infected women with CD4 count of $\leq 350$ cells $/ \mathrm{mm}^{3}$ was 7 times higher than in HIVinfected women whose CD4 count was $>350$ cells $/ \mathrm{mm}^{3}$, and this was statistically significant $(\mathrm{OR}=7.05 ; 95 \% \mathrm{CI}: 3.7-13.3$, $P<0.05$ ) (Table 5).

\section{Table 5.}

The pattern of $B V$ among $H I V$-positive pregnant women and their CD4 count

\begin{tabular}{|l|c|c|c|c|c|}
\hline CD4 cells $/ \mathrm{mm}^{3}$ & \multicolumn{5}{|c|}{ BV } \\
\hline & positive & negative & $P$ & OR & $95 \%$ CI \\
\hline$\leq 350$ & $71(67.0 \%)$ & $35(33.0 \%)$ & & 1.00 & \\
$>350$ & $21(22.3 \%)$ & $73(77.7 \%)$ & 0.000 & 7.05 & $3.7-13.3$ \\
\hline Total & $92(46.0 \%)$ & $108(54.0 \%)$ & & & \\
\hline
\end{tabular}

\section{Discussion}

This case-control study was done to determine the prevalence of $\mathrm{BV}$ among HIV-positive antenatal women, compared to their HIV-negative counterparts, and to relate the presence of $\mathrm{BV}$ to their immunological status at ABUTH, Zaria.

The prevalence of BV in both case and control group was found to be $33.2 \%$. The prevalence of BV among HIVinfected pregnant women in this study was $46 \%$ compared to $20.5 \%$ among HIV-uninfected women. This difference is statistically significant $(\mathrm{OR}=3.30, P=0.000)$, thus suggesting that $\mathrm{HIV}$ is a significant exposure risk for BV. Therefore, some HIV clinics also provide sexual health screens and test for BV as part of their care [10].

Demographically, in the HIV-positive pregnant group, BV was more commonly associated with tribe, religion, and parity. Tribe and religion may be associated with sociocultural habits, including risk practices that may include douching with vaginal washes or soaps; other things inserted in the vagina erroneously include tampons, pads, powders and sprays. The use or non-use of contraceptives and the type might affect the prevalence of $\mathrm{BV}$ : hormonal contraceptives are protective of $\mathrm{BV}[8,11]$ while intrauterine contraceptive devices have been associated with increased susceptibly to BV $[10,12]$. These are all dependent on tribal and religious beliefs [12]. The prevalence of BV was highest among multiparous (1-4) women $(54 \%)$ compared to nulliparous women, and this was statistically significant. This could be due to the fact that multiparous women are more likely to have had more sexual intercourse, which is a known risk factor, and also because of the drop in cellular immunity in this group of patients $[8,13]$. Parity was not a significant factor among the HIV-negative group.

Demographically, in the HIV-negative group, BV was 
more commonly associated with the level of educational attainment and the age of subject. It was higher among those with no form of education. Low education has been linked to higher BV-risk in the literature [14]. It was more prevalent in the age group 30-34 years (37.8\%), which was significant. This could be due to the fact that this age group is in the active reproductive period and patients are more sexually active. Other studies showed a high prevalence in the age group 25 to 29 years $[14,15]$.

Demographically, in both groups, BV was more prevalent in the second trimester though this was not statistically significant. This could be as a result of late booking: mean gestational age at booking was 20 weeks. All the women studied were married except two that were widowed. Though the prevalence of BV was equal among women in monogamous and polygamous unions, women who were BVnegative were more likely to be in monogamous marriages than in polygamous marriages. This could be explained by the fact that those in monogamous settings are less likely to have multiple sexual partners than their polygamous counterparts. Having multiple sexual partners has been identified as a risk factor $[10,16,17]$, although the number of partners over time was not significantly associated with BV. Many (13.5\%) were too shy to give information on their number of partners, considering its sensitive nature, especially in northern Nigeria were this study was conducted.

In HIV-positive pregnant women, considering one of the criteria for instituting HAART (CD4 count), among those with CD4 count $\leq 350$ cells $/ \mathrm{mm}^{3}$, the prevalence of clinical BV was $67 \%$. This was 7 times higher than in those who had CD4 counts greater than 350 cells $/ \mathrm{mm}^{3}$, in whom the prevalence rate was $22.3 \%$ and was similar to the prevalence rate of $20.5 \%$ among HIV-uninfected pregnant women. It is possible that HIV infection alters the local immune mechanism in the lower genital tract, which puts those women with HIV at higher risks for the $\mathrm{BV}$ organism to thrive and proliferate in the vagina $[8,17]$. Furthermore, studies have shown that HIV load in the genital tract correlates positively with BV and inversely with the absence of BV $[1,12,17]$. The increase in HIV load in the genital tract of BV women leads to more exposure to this high viral load during the process of labor and delivery, thereby increasing the risk of mother-to-child transmission of HIV if this infection is not identified and treated in pregnancy $[1,2]$. These results, therefore, imply that identification and treatment of $\mathrm{BV}$ is an important strategy in the prevention of HIV transmission, particularly with respect to mother-to-child transmission.

Cell-mediated immunity is an important component of protection against genital tract pathogens; the higher the number of memory T-cells the better protection against infections [2]. T-cells are the main target of HIV in the blood, and they act as the host the virus needs to replicate. One important feature of the T-cell's structure is the CD4 receptor site; once these "coordinator" T-cells are hijacked, the immune system is annihilated, leaving the body open to infections [2,17]. Therefore, the CD4 count is a good reflector of the immune system; hence the lower the CD4 count, the higher the prevalence of $\mathrm{BV}$, as shown in this study.
To detect clue cells, the gram stained smear has been found to have higher sensitivity and specificity $[11,12,15]$. Despite this, none of the 4 criteria was as accurate as it should have been, hence the need for the composite criteria $[14,18,19]$. It is also possible that not all BV patients had the offending organisms diagnosed. This may be due to the use of antibiotics or antiseptic soaps or preparations for douching prior to presentation at the clinic $[14,19]$.

\section{Conclusion}

This is probably the first case control study in Nigeria that compared the prevalence of BV among pregnant women who are HIV-positive and their HIV-negative counterparts and that related the presence of $\mathrm{BV}$ to the immunological status of the HIV-positive antenatal group. The prevalence of $\mathrm{BV}$ infection among HIV-infected pregnant women is 3 times higher than among their HIV-negative counterparts. Likewise, the prevalence of $\mathrm{BV}$ is 7 times higher among HIVinfected pregnant women whose CD4 counts were $<350$ cells/ $\mathrm{m}^{3}$ compared to those whose CD4 were $>350$ cells $/ \mathrm{mm}^{3}$ in ABUTH, Zaria.

\section{Competing interests}

The authors declare that they have no competing interests.

\section{Acknowledgements}

We would like to thank matron Alalade and the nurses under her care, the staff of the PEPFAR/APIN clinic for their co-operation and assistance, Mr. Bawa and Mr. Iliya who did the staining, Dr. (Mrs.) Giwa (now HOD of Microbiology) and Dr. Abdulazeez (a senior registrar in Microbiology), as well as Mrs. Odengle from computer science department, Mr. M.B. Bana and Dr. Popoola from Community Medicine of ABU Zaria for their assistance in the statistics and SPSS software implementation, and Dr. A. Obiniyi from Maths department for the technical assistance.

\section{References}

1. Atashili J, Poole C, Ndumbe PM, Adimora AA, Smith JS. Bacterial vaginosis and HIV acquisition: a meta-analysis of published studies. AIDS. 2008;22(12):1493-501.

2. Spear GT, St John E, Zariffard MR. Bacteria vaginosis and human immunodeficiency virus infection. AIDS Res Ther. 2007; 4:25.

3. Adinma JIBD, Nneka Okwoli R, Agbai AO, Unaeze NC. Gardnerella Vaginalis Vaginosis in Nigerian Igbo Women. Trop J Obstet Gynecol. 2001; 17:21-23

4. Kwasi A. Apea-Kubi, Bright Sakyi, Shinya Yamaguchi and David Otori-Adjei. Bacterial Vaginosis, Candida albicans and Trichomonas vaginalis Infection in antenatal and gynaecological patients in Ghana. Trop J Obstet Gynecol. 2005; 22: 108-112

5. Hillebrand L, Harmanil OH, Whiteman V, Khandelwai M. Urinary tract infection in women with bacterial vaginosis. Am J Obstet Gynecol. 2002; 186(5):916-7.

6. Behets F, Andriamiadana J, Rasamilalao D, Ratsimbazafy 
N, Randrianasolo D, Dallabetta G, et al. Sexually transmitted infections and associated socio demographic and behavioral factors in women seeking primary care suggest Madagascar's vulnerability to rapid HIV spread. Trop Med Int Health. 2001; 6(3):202-11.

7. Hay PE, Lamont RF, Taylor-Robinson D, Morgan DJ Ison C, Pearson J. Abnormal bacterial colonization of the genital tract and subsequent preterm delivery and late miscarriage. BMJ. 1994;308(6924):295-8.

8. Sewankambo N, Gray RH, Wawer MJ, Paxton L, McNaim D, Wabwire-Mangen F, et al. HIV-1 infection associated with abnormal vaginal flora morphology and bacterial vaginosis. Lancet. 1997; 350(9007):546-50.

9. Amsel R, Totten P, Spiegel CA, Chen KC, Eschenbach DA, Holmes KK. Non-specific vaginitis. Diagnostic criteria and microbial and epidemiological associations. Am J Med 1983;74(1):14-22

10. Koumans EH, Kendrick JS; CDC Bacterial vaginosis Working Group. Preventing adverse sequelae of Bacterial vaginosis: a public health program and research agenda. Sex Transmitted Dis. 2001;28(5):292-7.

11. Brand JM, Galask RP. Trimethylamine: the substance mainly responsible for the fishy odor often associated with bacteria vaginosis. Obstet Gynecol 1986; 68(5):682-5.

12. Sha BE, Zeriffard MR, Wang QJ, Chen HY, Bremer J, Cohen M.H, et al. Female genital tract HIV load correlates inversely with Lactobacillus species but positively with bacterial vaginosis and Mycoplasma hominis. J Infect Dis. 2005;191(1):25-32

13. Hiller SL, Krohn MA, Nuggent RP, Gibbs RS. Characteristics of three vaginal flora patterns assessed by Gram stain among pregnant women. Vaginal Infections and Prematurity Study Group .Am J Obstet Gynecol. 1992; 166(3):938-44.

14. Ileogben SA, Lawrence UO, Jude U, Joshua AO. Bacterial vaginosis in antenatal patients in Abakaliki, Nigeria. Trop J Obstet Gynecol. 2006; 23:100-4.

15. Adinma JIB, Okwoli NR, Agbai U, Unaeze N. Prevalence of Gadneralla vaginalis in pregnant women. Afr J Reprod Health. 2001; 5:50-5.

16. Gardner HL, Dukes CD. Haemophilus vaginalis vaginitis: a newly defined specific infection previously classified nonspecific vaginitis. Am J Obstet Gynecol. 1955; 69(5):962-76.

17. Hashemi F.B, Gbassemi M, Roebuck KA, Spear GT. Activation of human immunodeficiency virus type 1expression by Gardnerella vaginalis. J Infect Dis. 2000;179(4):924-30.

18. Anukam KC, Osazuwa EO, Ahonkhai I, Reid G. Association between absence of Lactobacilli PCR products and Nugent scores interpreted as bacteria vaginosis. Trop J Obstet Gynecol. 2005;22:103-7.

19. Hiller SL, Krohn M, Klebanoff SJ, Eschenbach DA. The relationship of hydrogen peroxide-producing Lactobacilli to bacteria vaginosis and genital microflora in pregnant women. Obstet Gynecol. 1992;79(3):369-73. 